Revista Iberoamericana, Vol. LXXIII, Núm. 218, enero-marzo 2007, 111-128

\title{
EL RELAJO COMO REDENCIÓN SOCIAL EN LOS RITUALES DEL CAOS DE CARLOS MONSIVÁIS
}

\author{
POR \\ Tania Gentic-Valencia \\ University of Pennsylvania
}

En Los rituales del caos (1995) Carlos Monsiváis muestra una imagen de la nacionalidad que, a pesar de pertenecer al género de la crónica, se inserta en la larga tradición ensayística mexicana que intenta identificar lo “mexicano”. Pero la nacionalidad que presenta Monsiváis en este texto difiere de la de los ensayistas mexicanos como Octavio Paz, Samuel Ramos, Carlos Fuentes y otros por ser más inclusiva del sujeto marginado y por apoyarse más en una noción de la mexicanidad que se fundamenta en postulados posmodernos en vez de en la idea convencional de la nación. ${ }^{1}$ Varios críticos han comentado la dedicación de Monsiváis a promover una democratización del país a través de sus observaciones sobre la subalternidad. ${ }^{2}$ Wilfrido Corral nota: "Para [Monsiváis] la cultura es un conjunto de disciplinas que hacen posible la cohesión y organización entre los miembros de una determinada sociedad” (38). Así, María Eugenia Mudrovcic ha indagado a profundidad la cultura como aparece en Monsiváis, llamando la crónica de éste un "relato interpersonal y arqueológico de México" que "instala lo popular urbano en el centro del debate nacional [...proponiendo una] teoría monsivaíta de la identidad mexicana” (“Cultura” 30). ${ }^{3}$ De acuerdo con la intersección de lo popular y lo oficial que estas críticas subrayan, demuestro aquí que, además de concebir una identidad mexicana diferente de la tradicional que incorpore lo popular, la familiaridad de Monsiváis con los discursos académicos, culturales y literarios permite que el texto suyo, interpelando e interpelado en esta red de discursos, se crea capaz de actuar positivamente sobre la cultura que describe. ${ }^{4}$

\footnotetext{
${ }^{1}$ Para una historia general del ensayo latinoamericano -y en especial del cambio desde lo nacional hacia lo posmoderno- véanse los dos estudios de Martin Stabb.

${ }^{2}$ Como bien señala Ursula Kuhlmann, en la historia de la crónica mexicana se puede decir que este proyecto de representar la voz del sujeto excluido comienza en las crónicas escritas después de 1968, aunque sigue un patrón ya establecido por las crónicas de la Revolución Mexicana. Esta tendencia de representar al sujeto sin voz política aparece también en las obras de Elena Poniatowska, Luis González de Alba, Renato Leduc y Vicente Leñero (205).

${ }^{3}$ Para Mudrovcic, esta "identidad monsivaíta" estriba en la diferencia que presenta Monsiváis entre "cultura nacionalista (o lo que percibe como monoidentidad cultural impuesta desde arriba) y cultura nacional (o multi-identidades defendidas desde abajo)” (31).

${ }^{4}$ Para Monsiváis la política, la sociedad y la cultura están estrechamente ligadas. La teoría cultural de Monsiváis se preocupa más por desigualdades estructurales que por detalles específicos de la
} 
Recurriendo al relajo como forma de comentario social que además sirve de estructura retórica para la crónica, Los rituales del caos propone invertir la noción tradicional de la mimesis para que la palabra escrita no sólo refleje, sino que también constituya otra realidad nacional posible.

Las desigualdades de clase en la nación han constituido una parte fundamental de la obra de Monsiváis desde sus comienzos, pero las ideas que presenta sobre la identidad nacional de las masas han cambiado en los últimos años. Mientras que en Entrada libre (1987), el trabajo cronístico anterior a Los rituales del caos, ${ }^{5}$ las descripciones del sujeto marginado enfatizaban los desastres naturales, políticos o sociales como justificación para exigir una redistribución del poder para que incluyera al sumiso en la construcción de la sociedad, ahora Monsiváis no propone un desmantelamiento de las estructuras sociales, políticas y económicas que hasta este momento han determinado lo nacional. Al contrario, en Los rituales del caos el cronista evoca a través de la descripción y estructura retórica de la diferencia una inclusión futura de todos los elementos de la sociedad que se base en -aun cuando resistan- las realidades ya existentes. De esta forma, como correctamente señala Ignacio Sánchez-Prado, Los rituales del caos se diferencia de los trabajos anteriores “militantes” de Monsiváis, en los cuales el cronista partía de la noción de que la nación consistía en una oposición rígida entre las instituciones de poder y los sujetos desprovistos de éste. En este sentido, demuestra que en el mundo posmoderno de Los rituales del caos las oposiciones rígidas de los binarismos son reemplazadas por la influencia mutua de dos polos dialécticos funcionando en yuxtaposición el uno al otro (18). ${ }^{6}$

La premisa fundamental del argumento de Los rituales del caos es que lo que antes se concebía como el caos de las masas -y que se oponía al orden oficial- está regido por un orden, así como las instituciones estatales, y por unas estructuras de reproducción que aseguran la repetición de un comportamiento que, aunque diferente de la norma, debe ser

política o la sociedad. Por eso, cualquier discrepancia entre un grupo de sujetos y otro (ya sea por diferencias de bienestar económico, raza, religión, etnia, sexo, etc.) es interpretada como representativa del problema endémico de la democracia y modernidad incompletas de la sociedad mexicana.

${ }^{5}$ Aunque ha publicado por más de treinta años en varios periódicos y revistas, entre ellos Nexos, La Jornada y El Día, Monsiváis también ha producido varias colecciones de crónicas: Días de guardar (1970), Amor perdido (1977), Escenas de pudor y liviandad (1981) Entrada libre (1987) y Los rituales del caos (1995).

${ }^{6}$ Oponiéndose a las críticas de Linda Egan y María Cristina Pons, Sánchez-Prado ilustra que la mitocrítica que sostiene las lecturas del caos en Monsiváis -planteando la noción de un caos "bíblico-prehispánico", precientífico o metafórico como forma de evitar o combatir el consumo y el poder capitalistas- ya no funciona en el mundo paradójico de la diálectica. Sánchez-Prado contribuye también con una lectura de la escena clave sobre la Virgen de Guadalupe -a la cual me refiero más adelante en este artículo- que deshace la idea de Egan de que Monsiváis tiene “"una fe durable en la voluntad y capacidad del pueblo mexicano para prosperar'” (citado en Sánchez-Prado, 20). Como espero demostrar aquí, el cambio en la concepción de la nación que identifico en Los rituales del caos no es exactamente la posibilidad del subalterno de "prosperar", sino la oportunidad de todos los mexicanos de liberarse de las constricciones sociales de la nación como ha sido concebida tradicionalmente. 
reconocido como “mexicano”. ${ }^{7}$ La concepción de estas prácticas individuales responde a las teorías de Althusser sobre la ideología y propone rituales alternativos a los que funcionan a través de los aparatos del estado, con el fin de (re)producir una ideología distinta, una nueva práctica de la marginalidad que escape a las condiciones del binarismo centro-margen tradicional para constituir una marginalidad poderosa en la cual participe todo mexicano. A través de una colección de viñetas y descripciones que se enfocan en las muestras culturales mexicanas que se desvían de las normas oficiales -salpicada de unas "Parábolas de las postrimerías" que presentan una visión a veces teórica, a veces imaginada, de estos mismos fenómenos culturales-, Monsiváis vincula ciertas prácticas periféricas e ilustra las características que tienen en común. ${ }^{8}$ El autor no expresa explícitamente las conexiones entre ellas; más bien utiliza el ensayo como un instrumento sinóptico que, al repetir descripciones de actuaciones experimentadas en diversas esferas de la nación y recurrir a una variedad de voces narrativas, ${ }^{9}$ sugiere un modelo de inclusión y repetición de esta nueva versión de "lo mexicano".

Entre los rasgos que conectan a los fenómenos sociales están: la participación de las masas -un conglomerado que para Monsiváis representa a todos los sujetos que carecen de poder en tanto sus actos no alcanzan el nivel de lo oficial; la ritualización de unas prácticas que al surgir parecen brotar espontáneamente de los márgenes de la sociedad; y el papel del espectáculo (ahora muchas veces televisado) en la manifestación de estos ritos “caóticos”. Mediante descripciones escénicas se demuestra cómo las operaciones reproductivas y rituales de las instituciones estatales también ocurren en las prácticas que caracterizan a los márgenes de la sociedad, nivelando así las distinciones entre el centro y el margen. La equivalencia creada entre los ritos tradicionales oficiales y los que provienen de las masas posibilita para Monsiváis un sentido de lo mexicano más abierto que incorpora a todo sujeto en la experiencia nacional.

\footnotetext{
${ }^{7}$ Como nota María Cristina Pons, el caos y el orden aparecen como temáticas centrales desde muy temprano en la obra crónistica de Monsiváis (126). Sánchez-Prado, Glantz, y Egan también contribuyen con planteamientos al respecto.

${ }^{8}$ María Eugenia Cossío hace una lectura bajtiniana de las crónicas de Monsiváis, caracterizándolas como elementos de un "diálogo intratextual" (140). Cossío establece una conexión entre los acontecimientos descritos en escenas individuales y los diferentes títulos del autor que permite un acercamiento a la obra completa de Monsiváis. Mi lectura de su obra no se limita al diálogo esquemático en que "el episodio precedente configura al que le sigue y es, a su vez, configurado por éste” (Cossío 140). Me parece más convincente considerar la relación intratextual casi como un aura nebulosa de temas compartidos que están siempre presentes en las escenas individuales que escribe Monsiváis y que vincula una escena a las otras y un texto a los otros.

${ }^{9}$ En su análisis de Días de guardar (1971), Juan G. Gelpí señala que esta estrategia retórica de utilizar una multitud de identidades diferentes para formar parte de una colectividad más amplia contribuye a la ironía del texto: "In order to avoid a relationship marked by extreme distance from the crowd, Monsiváis's subject develops a series of 'identities' that reveal an ironic stance. $\mathrm{He}$ becomes the 'Instantaneous Sociologist', the 'pop psychologist', the 'Sudden Theoretician', and the 'Immediate Theorist'” (214). A su vez, John Kraniauskas constata que la heteroglosia bakhtiniana que parece estar presente en los textos de Monsiváis acerca la retórica cronística del mexicano a la retórica novelesca; así, arguye Kraniauskas, el autor tiene recurso a la misma variedad de voces alternativas, las cuales contribuyen a la narración "not merely in order to legitimize his portrayal [of society], but to provide the reader with alternative centres of narrative authority" (xi-xii).
} 
Una de las características más destacadas de los rituales que se experimentan en los márgenes es la participación de las masas, especialmente en los deportes como el fútbol, el boxeo y la lucha libre. En una de las primeras escenas del libro se describe cómo la celebración después de un partido de fútbol no es un rito caótico, como pareciera inicialmente. Los aficionados que luego de un partido celebran la victoria en las calles no actúan de manera espontánea y desordenada, sino que en el momento de actuar crean normas alternativas que utilizan un simbolismo nacional preestablecido. Describiendo, por ejemplo, la escena que observa un "aficionado" después de un partido de la Selección Nacional, en que el pueblo se congrega instintivamente en el mismo lugar, Monsiváis escribe:

[el observador] ve en su alrededor a los chavos envueltos en las banderas, lo que ya es ritual, y observa el verde, el blanco y el colorado en caras y brazos y torsos, y admira la variedad de rostros como máscaras, y recuerda a la chava sobre el toldo del camión con el brassiere improvisado que tomó de una bandera, y contempla a dos adolescentes con su taparrabos tricolor, y se rinde a la evidencia: este nacionalismo será a plazo fijo pero es novedosísimo. Los grandes símbolos ya forman parte del guardarropa más esencial. (36)

Los elementos compartidos por los sujetos mexicanos -las banderas, el tricolorconvierten en rituales predeterminados lo que Octavio Paz describe en El laberinto de la soledad (1950) como el caos de la fiesta, de tal manera que el aparente desorden siempre es regido por un simbolismo ya experimentado y conocido. ${ }^{10}$ Además, lo novedoso, lo espontáneo en el espectáculo público -el usar la bandera como ropa simbólica, por ejemplo-se ritualiza inmediatamente, asimilándose a los ritos tradicionalmente aceptados. Esta descripción de la integración de las masas y los símbolos nacionales se contrasta con la descripción del Mundial de Fútbol que Monsiváis incluye en Entrada libre, cuando los aficionados celebran la participación mexicana en las eliminatorias de manera tan unificada que alcanzan a solidificar un solo nacionalismo "genuino", aunque temporal (213). En esa obra, sin embargo, lo que parece ser un ““contrato’ o ‘pacto’ entre hegemonía y subalternidad” (Mudrovcic, “Cultura” 35), una “democratización desde abajo” -el patriotismo evocado por el fútbol- de hecho parte de una noción establecida e institucionalizada de lo que es la nación, y así desaparece-tanto como la “democratización” que supone representar- una vez que el partido se pierde (Monsiváis 211). ${ }^{11}$ En el intercambio de lo masivo y lo oficial de Los rituales, sin embargo, lo que se evidencia no

\footnotetext{
${ }^{10}$ Para más sobre la relación entre Octavio Paz y Carlos Monsiváis, vea el ensayo de Mudrovcic, "Carlos Monsiváis, un intelectual post-68”.

${ }^{11}$ La "democratización desde abajo" demanda -y alcanza- que "nadie desnacionalice quedándose en casa”, pero es efectuada porque la radio y los políticos instan a que todos participen en ella (211, 217). Luego, cuando se pierde el partido contra Alemania, eliminando la Selección mexicana del Mundial, desaparece el nacionalismo compartido que, según Monsiváis, se reconocía en "el uso incesante de la primera persona del plural" (219): "ya no se dice "Perdimos", sino "Perdió la Selección” (232). Los espectáculos con los cuales México termina el Mundial y que proponen enfatizar la cultura mexicana, demuestran "el desastre de una retórica nacionalista, que ya sólo dispone de un público cautivo: los propios funcionarios” (236).
} 
es un nacionalismo unificado pero temporal, sino la posibilidad de que existan varias prácticas nacionalistas no oficiales que son ejecutadas diariamente en diferentes espacios.

En la descripción del fútbol y otros ejemplos de Los rituales del caos, la televisión es el medio a través del cual la nación participa en estos ritos: todo sujeto que no participe directamente en la fiesta, aunque aislado físicamente por su distancia del suceso, está todavía ligado a los ritos “alternativos” practicados por las masas al verlos en la televisión. La referencia a los "rostros como máscaras” refuerza la naturaleza compartida del evento, ya que se sugiere una conexión participatoria que va más allá de lo visual; es decir, hay un basamento que, como aseveraron Ramos y Paz, constituye un fundamento de la nación mexicana. ${ }^{12}$ En Monsiváis, el basamento resulta identificar un nuevo terreno nacional no igual al centro tradicional, pero por lo menos mutualmente influenciado por influyente en ello; este espacio otro no es el espacio del margen per se, sino que es una nueva especie de otro que mezcla lo marginado con lo central.

La máscara tiene otro propósito también: además de vincular al sujeto marginado con un nuevo espacio otro compartido, también lo relaciona con el proyecto retórico de Los rituales del caos, que sostiene la posibilidad de que el texto tenga un efecto social -que pueda invertir la mimesis tradicional para que lo escrito refleje y además constituya otra realidad posible. A lo largo del libro, los sujetos que Monsiváis describe son homogeneizados bajo la rúbrica uniforme de "las masas", pero lo son de manera que esta "máscara" lingüística no es simplemente una fachada retórica sino una posibilidad de cambio social. ${ }^{13}$ En "La hora de la máscara protagónica”, vemos que "El Santo”, luchador libre cuya personalidad en el espectáculo se define por la máscara, tiene éxito porque se da cuenta de que ésta "(no [es] ocultadora sino creadora de su identidad)” (128). Por un lado, la referencia a la máscara de El Santo llama la atención a partir de varios debates vigentes en los años noventa sobre los disfraces y máscaras utilizados por los participantes en los espectáculos televisados de la lucha libre mexicana. ${ }^{14}$ A su vez, le permite a Monsiváis

\footnotetext{
${ }^{12}$ Me remito a El laberinto de la soledad de Paz y a El perfil del hombre y la cultura en México de 1934 de Ramos. Además de postular un trasfondo nacional compartido, ambos ensayistas buscan identificar un tipo mexicano que represente toda una cultura: en Paz, el pachuco cumple este papel, mientras que en Ramos el pelado es la figura característica nacional.

${ }^{13} \mathrm{La}$ aseveración de que la retórica se puede vincular a la resistencia también ha aparecido en el artículo de Mudrovcic, quien relaciona la retórica con el uso de lo camp en Días de guardar (1970) (“Cultura” 31-33). El artículo de Sebastiaan Faber, "La metonimia en una crónica de Carlos Monsiváis: Hacia un periodismo democrático”, también contiene un análisis detallado sobre el estilo neobarroco, la parodia, y el recurso a la sinécdoque y la metonimia como características determinantes de esa misma obra.

${ }^{14}$ Este debate es explicado por Heather Levi en "Masked Media: The Adventures of Lucha Libre on the Small Screen”. En los años noventa, hubo un cambio en la lucha libre al ser desdoblada en dos espectáculos distintos, el "tradicional" que se presentaba en vivo en los barrios pobres y el que se televisaba por primera vez en casi cuarenta años, incorporando muchos elementos de la lucha libre estadounidense. Según los tradicionalistas, los disfraces de los luchadores televisados que cubrían todo el cuerpo demostraban el fraude de la performance televisada al borrar la participación de la persona real que ocupaba el disfraz del personaje de la lucha, convirtiéndolo todo en ficción; los viejos modelos, sin embargo -que dejaban desnudas algunas partes del cuerpo, como los brazos, aun cuando se cubría la cara- mantenían una identificación directa entre la persona que ocupaba la
} 
oponer su proyecto al consabido argumento de Octavio Paz, quien arguye que la "verdadera” identidad mexicana yace bajo una fachada ocultadora; y se aparta de la noción de Paz de que lo identitario es lo que se esconde tras ella. De hecho, al asemejar su deportista al luchador libre de las Mitologías de Roland Barthes (Los rituales 132), Monsiváis nos indica que la superficie es la realidad accesible y, como tal, el escenario en el cual se puede actuar para promover cambios (125). La retórica de la crónica, entonces, constituye una acción, hecha real a través de la participación del lector que, al entender y luego identificarse con las masas descritas, vivirá de ahí en adelante otra experiencia de "lo mexicano".

Los ejemplos de estas manifestaciones culturales del marginado alternativo no se limitan a lo deportivo. Monsiváis dedica gran parte de su texto a los actos religiosos que se apartan de la ortodoxia católica conservadora. Al construir unos ritos al margen de los ya institucionalizados, el pueblo crea prácticas que además de ser definitivamente mexicanas son, como casi todos los ejemplos de Los rituales del caos, representaciones de las clases despreciadas económica, social o étnicamente. La Virgen de Guadalupe, afirma Monsiváis, ha sido representante de lo mexicano desde su primera aparición; en el siglo xx, ella se asocia con los menos afortunados:

A fines del siglo xx, en la Guadalupana se concentran las vivencias de la marginalidad y el desgarramiento, en ámbitos donde lo mexicano es sinónimo de orgullo recóndito o de inocencia sin protección. Ella, presente en la infancia de cada mexicano (sea o no católico), es el paisaje de las convicciones tutelares, el signo de la normalidad en la pobreza, el pretexto formidable para el ejercicio de la intolerancia. (41)

Como ocurre con el fútbol, en los ritos de la Virgen la televisión es fundamental para ayudar a los pobres a “adaptarse”, a sujetarse a la modernización, el ejemplo más reciente de un proceso que excluye a algunos segmentos de la población. Mientras el narrador observa en la televisión la veneración anual de la Virgen el 11 de diciembre, se pregunta: “¿Hasta qué punto es reverente a la antigua una muchedumbre cuyo alborozo también le viene de su condición televisable?” (43). La respuesta se hace obvia cuando el autor ve y escucha la presentación de la canción "Las Mañanitas” y nota que "La congregación está leyendo la letra de 'Las Mañanitas', en papelitos obsequiados a la entrada. Si el pueblo no se sabe de memoria 'Las Mañanitas', ¿qué destino le espera a la Constitución de la República?” (44-45). Más tarde concluye: “Lo cierto es que, apretujado en la nueva basílica, soy testigo del escamoteo: a la piedad que observa la sustituye la piedad que se siente observada” (46). El símbolo religioso y los medios de comunicación modernos se combinan para mantener la desigualdad entre las clases sociales, asegurando que la posición marginada se reinscriba en lo nacional. El hecho de que los participantes no saben de memoria las palabras de una canción tan íntimamente relacionada a la identidad

máscara y la máscara misma, posibilitando una cierta correspondencia entre el espectáculo y la realidad (Levi 360). Otro elemento interesante y vigente del texto de Levi para nuestro estudio es el análisis que provee sobre el efecto de la lucha libre en la resistencia social de las clases populares. A partir del año 1987, se crean en México "luchadores libres sociales”, como Superbarrio Gómez y Ecologista Universal, que participan en manifestaciones y acosan a los políticos que se niegan a reconocer las necesidades de las clases marginadas (346-47). 
mexicana atestigua esta incorporación forzada, mientras señala la ironía de la actualidad mexicana, la cual subyace todo el relato de la Virgen. A la vez, el ritual del pueblo se transforma para conformarse con las novedades tecnológicas dominadas por las instituciones del poder y, así, supera la separación estricta de lo popular y lo ofical, participando en un medio normalmente reservado para la esfera del poder.

La religión y el deporte televisados presentan prácticas de las masas que ocurren fuera de lo institucional, pero que se repiten hasta hacerse rituales. No obstante, antes de la invención de la televisión, estos procesos dialécticos funcionaban sin esa tecnología para realizar la misma operación de sincretizar la cultura dominante con la marginada. Los casos históricos que Monsiváis incluye en Los rituales del caos se vinculan a los ejemplos ya citados por el común denominador del rito como espectáculo y por el tono irónico que recorre todo el libro. Por ejemplo, hablando de los eufemismos del porfiriato y del uso positivista de la estatua y del monumento público como educación cívica, Monsiváis se burla del centro directamente, presumiendo una conexión con sus lectores -creada por la educación, el conocimiento de la historia y el mismo sentido de desencanto frente a un gobierno tiránico- para comentar la estructura y el espectáculo del poder: "En el ánimo de la época (eufemismo para hablar del gusto y las necesidades políticas de los poderosos), las estatuas son medios de comunicación masiva” (146). ${ }^{15}$

Vincular la esencia de una sociedad hispana con el humor, como hace Monsiváis al burlarse de la tradición cívica en México, no es nuevo. ${ }^{16}$ Jorge Mañach se refiere a la práctica humorística del choteo como sustancial del carácter cubano en su Indagación del choteo (1928) y las obras de otros cubanos, como Guillermo Cabrera Infante y Severo Sarduy, o del puertorriqueño Luis Rafael Sánchez, también refuerzan la relación entre el humor y el carácter nacional. Un acercamiento crítico al fenómeno del humor como relevante a la hispanidad que resulta llamativo para nuestra discusión indaga la relación entre nación y humor a través de las estructuras retóricas y estéticas que la sostienen: Erica L. Miller y Efraín Barradas han comentado esa relación con respecto al humor caribeño, aunque no tocan la cuestión mexicana del relajo. ${ }^{17}$ Fenomenología del relajo (1966) de

\footnotetext{
${ }^{15}$ Sin lugar a dudas, el comentario sobre el "ánimo de la época” hace hincapié también en los problemas del porfiriato, cuyo énfasis en la apariencia de la ciencia no siempre cuadraba con las realidades que producía. Como demuestra Joseph Cotter, muchos de los programas porfiristas se contradecían entre sí, como el hecho de que se instaba a la reproducción acelerada de la población, aunque la producción agrónoma no alcanzaba a subir en concordancia con el crecimiento del pueblo, condición que contribuyó en gran parte a las quejas revolucionarias. Irónicamente, después de la Revolución muchos agrónomos revolucionarios propusieron planes de acción muy similares a las ideas no exitosas del gobierno de Díaz (20-21).

${ }^{16}$ Una nueva colección de ensayos sobre el humor editada por Paul W. Seaver demuestra la extensión y variedad de los discursos humorísticos de la tradición literaria hispánica.

${ }^{17}$ Miller demuestra que al desdoblar el concepto del fenómeno nacional del choteo en "choteo benigno" y "choteo pernicioso", Mañach recurre a una técnica retórica necesaria que le permite convertirse en agente de cambio en la política cubana de los años veinte. Efraín Barradas elucida una relación ambigua y esquiva entre clase social, (pos)colonialismo, estética y nación en el humor caribeño, relacionándolo con sus precedentes españoles. Vincula la política de la nación en España, Cuba, Puerto Rico y la República Dominicana con la estética de lo cursi, lo camp y lo kitsch, y las prácticas humorísticas del choteo, la bachata y la chercha. Aunque admite que las definiciones que
} 
Jorge Portilla, escrita tres décadas antes de Los rituales del caos, es el texto imprescindible sobre este fenómeno social en México; además, es esencial para entender el proyecto de redención social que sirve de base al texto de Monsiváis. Lo que diferencia el uso del humor en Monsiváis de las fenomenologías que -en la obra de Mañach tanto como en la de Portilla- proponen una equivalencia entre la práctica de humor y la nación es que en las crónicas de Monsiváis, el uso retórico del relajo crea una distancia textual del objeto que describe, lo que paradójicamente señala un acercamiento crítico a los procesos culturales masivos en México (Kraniauskas xiv). Así, el relajo de Monsiváis, como las relaciones dialécticas que hemos visto en Los rituales del caos, desmiente la noción tradicional de que existe una relación directa y unívoca entre las prácticas culturales y la identidad nacional. ${ }^{18} \mathrm{El}$ elemento del ensayo de Portilla que más se destaca para nuestros propósitos, sin embargo, es el concepto de la comunidad que se requiere para que el relajo individual funcione como burla de -y reto a- la autoridad (23).

Según Portilla, el humor se convierte en relajo cuando el público que oye el chiste lo reconoce como tal y como reto al discurso del poder. En Monsiváis, la comunidad de lectores es necesaria para activar la palabra escrita y liberar la sociedad mexicana de sus jerarquías de poder y restricciones sociales, primero entendiendo la broma y luego riéndose de ella. ${ }^{19}$ Eso requiere que el lector entienda las referencias que se incluyen en el texto, porque de no ser así, el humor no le sería evidente. Precisamente por la naturaleza ambigua de la crónica -todavía dependiente de ciertas “verdades” o noticias aceptadas como reales para ser efectiva, pero a la vez suficientemente distanciada de lo objetivo para permitir opiniones del escritor- Monsiváis supone un lector hipotético que confía en la veracidad de lo que dice el autor (Egan, Carlos Monsiváis 100). ${ }^{20} \mathrm{Al}$ describir no sólo momentos históricos sino también actuales -hablando entre otras cosas de sucesos que aparecen en los noticieros diarios, anuncios publicitarios y lugares reales- el lector puede imaginarse como partícipe en las escenas que Monsiváis describe. El elemento de verdad

provee son esquivas, parte de la noción de que lo cursi proviene de una España burguesa decimonónica y que el choteo y la bachata resisten el poder colonial asociado con ello; la chercha de la República Dominicana, un país que nunca tuvo la relación antagónica con la metrópoli que tuvieron Puerto Rico y Cuba, por eso tampoco recurre al humor como forma de resistencia.

${ }^{18}$ En este sentido, el relajo se relaciona más con la "cultura nacional” multiidentitaria de Monsiváis que Mudrovcic describe que con la "cultura nacionalista” monoidentitaria de él (véase la nota 3); en Los rituales del caos, el relajo también adquiere un poder de redención similar al que, según Mudrovcic, ejerce lo camp en Días de guardar (“Cultura” 31-33).

${ }^{19}$ Los rituales del caos vuelve así a un noción propuesta por Monsiváis anteriormente en La poesía mexicana del siglo XX (Antología) (1966), en la que se establece un vínculo entre el lenguaje, el poder y el humor: "Una prueba evidente de este continuo vasallaje a una lengua que,[...] por miedo o timidez o rencor, no nos decidimos a maltratar o poseer, es la ausencia de humor en nuestras letras [...] El humor que burla con y del lenguaje son signos de madurez y civilización” (Egan, Carlos Monsiváis 137).

${ }^{20}$ Egan enumera otras condiciones de la crónica que se basan en la "verdad" presentada por el autor y aceptada por el lector "competente" como tal, entre ellas el uso de la documentación, la inclusión en el texto del lugar de publicación y la mención de fechas y lugares específicos (Carlos Monsiváis 99-103). El capítulo 4 de su libro contiene una discusión franca y polémica sobre la aplicación de la palabra "verdad" a ciertas características de la crónica, lo cual es importante, según ella, porque el manejo creativo de una verdad presumida distingue a la crónica del periodismo y de la ficción. 
(real o sólo imaginado por el lector) aparece en los chistes o burlas en las crónicas de Monsiváis y crea una comunidad de lectores que se ríen, no de los comentarios de Monsiváis, sino con ellos y con el narrador mismo. En esos momentos clave, la crónica deja atrás su condición periodística, convirtiéndose en relajo.

A diferencia del reportero cuyo texto da una versión seria de lo que cuenta, Monsiváis genera una comunidad de "relajientos" cuya risa combate el valor normativo nacional de la realidad vivida. ${ }^{21}$ Instigada por la ironía y el humor de sus crónicas, la risa compartida de los lectores masifica el gesto de tomar distancia de y negarse a participar en los ritos del centro. Al igual que los espectadores de los programas de televisión que participan en los ritos del caos mirándolos, la relación entre texto y lector propone una participación activa del lector en determinar el significado social de las masas mexicanas que son descritas en el texto; por el poder mimético de éste, las masas alternativas que Monsiváis describe también constituyen la realidad que está viviendo el lector. La proliferación de creencias culturales, sociales y económicas de una sociedad heterogénea que, como los millones de pasajeros que toman el metro de la Ciudad de México cada día, representan “el caos en una cáscara de nuez" (Monsiváis, Los rituales 111), define una colectividad diversa de sujetos; la diversidad de estos, con sus prácticas como actores y como observadores, constituye una vivencia de lo mexicano que no cuadra con la idea de una nación mexicana unitaria que presume la oficialidad del país. ${ }^{22}$ Tal inclusividad imaginada requiere una empresa escrituraria que active la unidad social mediante el poder de la palabra. Así, la crónica de Monsiváis se vislumbra a sí misma como una herramienta para convertir al sujeto mexicano en partícipe de un proyecto colectivo de liberación y autonomía social.

La praxis estilística y formal que Monsiváis utiliza en su texto para crear la posibilidad de esa otra realidad mexicana la constituye su uso del paréntesis. El espacio parentético -como la máscara antes descrita- no es sólo un mecanismo retórico, sino el puente entre la descripción de una situación y la posibilidad de su transformación. Desde el prólogo del texto se presenta una homología entre la intervención textual parentética y la libertad posible del sujeto mexicano, ambas de las cuales dependen de su relación con el humor: "La diversión genuina (ironía, humor, relajo) es la demostración más tangible de que, pese a todo, algunos de los rituales del caos pueden ser también una fuerza liberadora” (16). La diversión -que, como el humor, constituye la desviación de una trayectoria establecida-es el fundamento de la liberación social del sujeto de las jerarquías rígidas de poder. La realización textual de esta liberación se inaugura y define en el texto con el paréntesis que explica lo que es la diversión: “(ironía, humor, relajo)”. Al reírse con

\footnotetext{
${ }^{21}$ Para un análisis antropológico del relajo, ver el estudio de Miguel Díaz Barriga, quien subraya la presencia de esta estrategia humorística en uno de los sujetos estudiados por el antropólogo Oscar Lewis en Five Families: Mexican Case Studies in the Culture of Poverty.

${ }^{22}$ Es necesario enfatizar aquí que las masas no constituyen en Monsiváis solamente una liberación o reivindicación positiva de México; siguiendo la tradición modernista latinoamericana; para él a veces las masas también representan una molestia, una inconveniencia. La diferencia entre Monsiváis y los escritores anteriores es que Monsiváis acepta que las masas no se van; es más, todo mexicano constituye parte de las masas ya, y por eso la nación tiene que incluirlas en su construcción, tanto social y política como identitaria.
} 
el humor parentético, el lector no sólo reconoce las desigualdades representadas por la diferencia entre el discurso normativo y el relajo subversivo, sino que participa activamente en una resistencia a la norma.

Para ver más detalladamente cómo funciona esta instrumentalización de la retórica textual para producir una nueva sociedad mexicana, volvamos al tema de la religión. En una sección de la crónica, Monsiváis discute un fenómeno particularmente evocativo del tejido creado por la interpolación de las ideologías nacionales y las prácticas marginales: los curanderos espirituales, que representan una opción diferente de las prácticas paradigmáticas que operan en los espacios institucionales de la Iglesia Católica, la medicina, la economía y la geografía. En las décadas de los años veinte y treinta, por ejemplo, el Niño Fidencio, a quien Monsiváis identifica como uno de los "protagonistas" de los ritos alternativos, gana notoriedad porque se cree que su devoción religiosa le permite curar aflicciones ante las cuales la medicina moderna es impotente. Huérfano pobre que vive en el campo y sirviente desde niño de un latifundista rico, a los veintinueve años Fidencio ya es conocido en la provincia de Nuevo León por sus dones curativos y su dedicación a Dios, que lo convierten en un hombre venerado cuyas habilidades captan la atención tanto de los pobres afligidos como del presidente de la República. Es llamativa la lista de sus terapias que ofrece el texto, y que combinan lo religioso, lo medicinal y lo psicológico en prácticas que atraen la atención de las masas:

\begin{abstract}
Logoterapia: un "psicoanálisis primitivo”. El paciente da cuenta de sus valores y metas. Kineterapia: el Niño columpia a paralíticos, mudos y dementes.

Impactoterapia: el Niño arrojaba sobre la muchedumbre, desde una azotea o prominencia, las frutas y huevos que le obsequiaban. La muchedumbre se agolpa creyendo que si el proyectil toca al miembro enfermo, se curarán: el tomatazo, guayabazo o manzanazo lanzado por el Niño equivale a una bendición. También Fidencio provoca choques psicológicos en el paciente dejándolo en la jaula de un puma (sin dientes y garras). Según los testimonios, esta terapia resulta infalible con los sordomudos. (101)
\end{abstract}

Efectivos o no, los tratamientos del Niño -cuyos detalles sin duda son presentados con el propósito de hacer sonreír al lector- sirvieron para unificar a las masas pobres y brindarles unas posibilidades de cura distintas de las ofrecidas por la religión y la medicina convencionales. Ritos que fueron ritualizados por él y sus seguidores, no sólo mediante las prácticas antes descritas, sino también por las peregrinaciones de los pobres que lo visitaban. Cuando el presidente Calles visita al Niño para curarse de unos dolores no especificados, los ritos espirituales que Fidencio mismo había descrito como relacionados con una devoción religiosa que se corresponde con la pobreza (102) son practicados sobre la figura más representativa del poder. La incorporación de lo alternativo en lo nacional -y viceversa-significa un intercambio entre los dos sectores que, a pesar de estar completamente apartados el uno del otro en la sociedad mexicana, funcionan análogamente. ${ }^{23}$

\footnotetext{
${ }^{23}$ Esta interpretación de la época posrevolucionaria como caracterizada por un intercambio de poderes se asemeja al proyecto de Mary Kay Vaughan en su estudio de los programas educativos de los años treinta en México. Vaughan concibe la relación entre los profesores mandados por el estado y las localidades rurales a las que llegan como evidencia de un proceso de negociación en vez de como una imposición forzada del poder federal: "the real cultural revolution of the 1930s lay not in the
} 
Lo interesante de esta escena es que a la vez que se establece una equivalencia de poderes entre el Estado y el Otro, se inaugura un espacio de mayor autoridad para el marginado a través del paréntesis humorístico que se incluye en la representación de la “impactoterapia”.

En la descripción del lanzamiento de frutas como cura, se añade el comentario ya citado: “También Fidencio provoca choques psicológicos en el paciente dejándolo en la jaula de un puma (sin dientes y garras). Según los testimonios, esta terapia resulta infalible con los sordomudos" (101). Encerrar al paciente en una jaula con un puma parece horroroso a primera vista, pero la tensión narrativa decae cuando el lector se da cuenta del “secreto" de la terapia: el animal está “(sin dientes y garras)” (101). Esta diversión sintáctica que separa con un paréntesis del resto de la descripción el secreto guardado por el que controla el tratamiento alternativo -el curandero milagroso que representa al pobre marginado, el Niño Fidencio- relaja la seriedad del proceso curativo para abrir paso al sentido cómico de la aseveración de que "esta terapia resulta infalible con los sordomudos" (101). Como los protagonistas de esta crónica son el Niño Fidencio y el presidente de la República, la inversión social que sugiere la posición de poder que adquiere el curandero pobre sobre el presidente poderoso es recalcada para el lector cuando éste ve el efecto que el paréntesis tiene ante el discurso normativo, el cual tendría un tono serio (y espantoso) sin la presencia refrescante del relajo parentético. La inserción de comentarios parentéticos adicionales en el texto principal crea dos discursos en contrapunteo: el de la narrativa “normal”, sin acotaciones, y el de la subversión, constituido por el paréntesis. El paréntesis inaugura un espacio para la opinión alternativa, cómica o marginada que hace hincapié en la naturaleza monolítica del discurso serio de la narración, posibilitando una lectura alterna de lo normativo. El comentario cómico incluido en los paréntesis establece una complicidad entre la posición marginada y el lector, ya que éste participa en bromas "a escondidas" sobre el discurso oficial que, al operar en un espacio separado de las descripciones y críticas serias que constituyen el grueso de la crónica, adquieren un aspecto contestatario.

Espacios de humor e ironía, los paréntesis borran la frontera entre texto y sociedad, comentando sobre ambos a la vez y haciendo que el lector piense en lo que lee y lo que vive como experiencias relacionadas. Hablando de lo que significa ser habitante de la ciudad de México, D.F., ${ }^{24}$ por ejemplo, Monsiváis dice:

state's project but in the dialogue between state and society that took place around that project” (20). Según ella, esta perspectiva representa una historiografía posrevisionista; el revisionismo, explica, es una crítica a los gobiernos tiránicos de 1968 que quiere ver la Revolución Mexicana como un movimiento opresivo llevado a cabo por un estado opresivo (8). A diferencia de esos intelectuales influidos por la violencia de 1968, Monsiváis, como Vaughan, postula una relación no desigual entre el pueblo y el estado, que es en realidad una negociación entre los marginados y el centro.

${ }^{24}$ La relación entre el espacio de la ciudad y la crónica constituye el tema principal del libro editado por Boris Muñoz y Silvia Spitta, Más allá de la ciudad: crónicas y espacios urbanos. Como los textos de Los rituales del caos, las crónicas discutidas allí (incluso las de Monsiváis y el ensayo que él mismo proporciona a esa colección crítica) navegan entre las conceptualizaciones de la ciudad que se desarrollan en dos obras que, según Spitta, representan los límites de un continuo en el análisis de la ciudad latinoamericana: La ciudad letrada de Ángel Rama y La ciudad sumergida: aristocracia y plebe en Lima, 1760-1830 de Alberto Flores Galindo (12). La diferencia fundamental de estos dos textos depende de la misma dialéctica caos-orden que figura en el presente estudio sobre Los rituales del caos. 
Enumero algunos orgullos (compensaciones psicológicas):

- México es la ciudad más poblada del mundo (¡La Súper-Calcuta!)

- México es la ciudad más contaminada del planeta (¡El laboratorio de la extinción de las especies!) (19)

Los paréntesis que ponen en entredicho las frases declaratorias expresan el desencanto con la vida mexicana y el reconocimiento de que la ciudad capital no es un modelo de desarrollo apropiado a pesar de su poderío social, económico y político. ${ }^{25}$ En lo que parece ser una activación sintáctica de la sugerencia de Austin de que uno puede "do things with words”, la crónica de Monsiváis recalca los problemas de contaminación y sobrepoblación, representando la voz crítica de una sociedad marginada que no quiere vivir regida por los términos de la norma oficialmente aceptada. Este reto humorístico al discurso oficial que reside en los paréntesis textuales es la expresión retórica de la redención social del sujeto marginado.

Sánchez-Prado dice que bajo el modelo dialéctico de la relación entre centro y margen - o caos y orden- "los espacios de libertad y rebeldía florecen en medio de circunstancias que también los aniquilan poco a poco” (20). Si fuera consistente la aplicación de la dialéctica a la nueva nación imaginada en el texto de Monsiváis, este argumento sería suficiente para desmentir el proyecto de relajo que he ilustrado aquí, convirtiéndolo en un ciclo constante de construir y borrar posibilidades. Sin embargo, en realidad el reto que enfrenta la posibilidad de una nueva alternativa a la nación tradicional no proviene de la aplicación del concepto dialéctico al orden y el caos, sino de la falta de una aplicación consistente de ello. Con la relegación de la resistencia a lo dominante a los paréntesis, la jerarquía paradigmática que separa la norma de su desviación se repite: se mantiene un orden en que el peso retórico reside en el texto del argumento central, y que relega el comentario parentético crítico a una posición marginada y relativa al centro que limita necesariamente su potencialidad. ${ }^{26}$

${ }^{25}$ Un tema de análisis que surge de estos comentarios de Monsiváis es la relación entre la ciudad y el cronista. Muchas veces este vínculo invoca una discusión sobre el flaneur, tanto por su posición como observador como por las relaciones de poder que él maneja. Walter Benjamin describe al flaneur de París como un observador alejado de las desigualdades del mercado que rigen la vida en la ciudad (10). Muchas veces estudiada en Latinoamérica con respecto al periodo modernista, esta noción del flaneur ha pasado, más tarde, a describir la función social del cronista casi como etnólogo que ironiza el espectáculo del poder central (Corona 138). Otros críticos contemporáneos, como Adolfo Castañón, Gelpí y Mary K. Long, han dejado de lado la idea del flânerie para comentar específicamente las descripciones de la ciudad de México que aparecen en la crónica mexicana, enfocándose en los trabajos de Salvador Novo y Carlos Monsiváis, entre otros. Monsiváis mismo provee una biografía de su antecedente, Novo, en la cual se destaca la integración de la marginalidad en el centro urbano a través de la crónica; al no negar su homosexualidad, arguye Monsiváis, Novo es "el hombre marginal que obtiene el acatamiento de la sociedad que, moralmente, lo desprecia," así participando en el centro a la vez que lo reformula, haciéndolo más diverso (Salvador Novo 11). ${ }^{26}$ En esto, mi perspectiva difiere de la de Evodio Escalante, quien ve un corte radical entre las primeras obras de Monsiváis -como Días de guardar (1970), Amor perdido (1977) y Escenas de pudor y liviandad (1981) - y las más recientes, como Nuevo catecismo para indios remisos (1982) y Los rituales del caos. Según Escalante, las primeras obras representan una etapa trágica en Monsiváis, informada por el marxismo y las concepciones neocolonialistas que surgen en México 
Para demostrar este problema, me remito a un capítulo de Los rituales del caos en el cual Monsiváis retrata al artista Jesús Helguera, considerado uno de los "protagonistas" de las masas. Este capítulo sigue a otro titulado “La hora del gusto”, en el que Monsiváis afirma que, mientras el gusto es algo personal, hay ciertas normas artísticas, impuestas desde arriba y desde afuera que dominan la interpretación del arte. En "La hora del gusto", el cronista parece tomar una distancia irónica de sus comentarios sobre la noción élite de la superioridad del buen gusto sobre el malo; pero cuando habla de la función nacional de Helguera en el siguiente capítulo, Monsiváis asevera que su arte atrae a las masas precisamente porque éstas carecen de un gusto estéticamente informado. Los calendarios de Helguera atraen al público por su belleza mal juzgada, arguye Monsiváis, pero también porque permiten que los ineducados participen en el arte:

Ante los cromos/cuadros de Helguera, el espectador no renunciaba al "gusto verdadero" (que él nunca había poseído), ni al temperamento crítico (que nunca había ejercido), sino a la incredulidad respecto a sus posibilidades de juzgar lo bello. Metamorfosis instantánea: si la reproducción de Helguera me conmueve, no soy del todo ajeno al arte. (67)

Si bien Monsiváis ilustra el aspecto clasista del "gusto” en el capítulo anterior -ilustración que repite aquí con las comillas con las que se circunscribe al "gusto verdadero"- éste ahora pone en entredicho la resistencia a la norma que había postulado antes al cuestionar el "gusto verdadero", cuando con los comentarios parentéticos usados en esta sección se adhiere a la voz dominante otra vez. Distanciándose de la población marginada que compraba los calendarios de Helguera y que no entendía el "gusto verdadero” porque no tenía el aparato crítico con el cual evaluar el arte, Monsiváis privilegia una posición que excluye al sujeto tradicionalmente marginado por el Estado. Al hacer comentarios críticos parentéticos sobre el sujeto ineducado, el autor se aleja del mal gusto y de la falta de educación de las masas en el espacio reservado para la diversión y liberación del sujeto marginado, pues Monsiváis claramente dirige su texto a un destinatario educado que se identifica con esta perspectiva exclusivista. ${ }^{27}$

El comentario sobre Helguera, con sus paréntesis cómicos dirigidos a un público élite, es evidencia de la contaminación sintáctica del poder normativo sobre la presumida resistencia que representa el paréntesis. Se podría decir a primera vista que esta confusión entre la voz parentética y la voz autorizada es simplemente otro aspecto del proyecto de nivelación entre centro y margen que quisiera instituir Monsiváis como reflejo textual del nacionalismo mexicano más inclusivo que intenta crear. Pero esta confusión representa también la persistencia del centro sobre el margen. La inversión de dos polos opuestos

después de Fanon, mientras la ficción de Nuevo catecismo y las crónicas de Los rituales representan un cambio hacia lo paródico, en el cual el "exceso de patria acaba divsolviendo la idea de patria" (87). A mi ver, esta visión de la obra de Monsiváis como etapas separadas es demasiado tajante e ignora los residuos del (neo)colonialismo y la división de clases que persisten como estructuras determinantes incluso en la obra posmoderna que constituye el enfoque de mi análisis.

${ }^{27}$ Egan propone que Monsiváis dirige sus crónicas en gran parte a las clases altas porque quiere representar los marginados ante aquellos que viven una experiencia mexicana más privilegiada. A mi ver, la crónica perdería parte de este efecto porque los sujetos afectados no participarían en su propia "liberación” a través de la lectura. 
jerarquizados como estrategia niveladora no se sostiene en éste ni en otros ejemplos retóricos del texto, porque aunque el discurso normativo del centro puede desbordarse y ocupar el espacio humorístico del paréntesis, el margen no puede entrar en la discusión seria de los problemas de desigualdad social sino como relajo secundario. Tal intento de apropiación “contaminadora” del discurso serio por el irónico fracasaría porque existiría siempre una voz narrativa principal. Los paréntesis del relajo no pueden entrar en lo serio para privilegiar su cuestionamiento de la norma, mientras que el discurso dominante puede extenderse hasta ocupar cualquier espacio textual. Como dice Roger Bartra en su discusión del relajo de Portilla, aunque el relajo parecería ser un reto a los valores dominantes, éste sirve sólo para mantener vigente al estatus quo: "La práctica embrolladora del relajo, al ser incorporada al mito del alma nacional, se convierte en una trampa: el relajo institucionalizado también funciona como una diversión que encamina las protestas potenciales por un desvío que asegura el equilibrio y la permanencia de las relaciones de dominación” (163). Aunque apela a un nuevo "mito del alma nacional”, el texto de Monsiváis también incorpora una diversión humorística que siempre refuerza las "relaciones de dominación” mexicanas.

Lo verdaderamente problemático del argumento de Monsiváis, sin embargo, es que todos los ejemplos de lo “mexicano”-estén en conformidad con o en contra de las normasestán supeditados en última instancia a la idea de un México “ideal” que siempre quedará fuera del alcance de las prácticas del sujeto nacional, sea éste marginado o no. Monsiváis utiliza unas estrategias sintácticas que aluden a la relación entre texto y lector para inspirar la consecución "real” de un futuro mejor que sitúa el espacio contestatario de la crónica en lo parentético/cómico. Pero aunque pretende invocar la dialéctica, el uso del paréntesis la convierte en una dependencia de la oposición binaria entre centro y margen, suscribiendo una definición de la desigualdad social que no le permite indagar a profundidad qué es exactamente el centro. Homi Bhabha ha querido subvertir este paradigma de centro y periferia social, demostrando que la norma nacional es imposible de actualizar, ya que todo intento de vivirla constituye una actuación insuficiente: ${ }^{28}$

The scraps, patches, and rags of daily life must be repeatedly turned into the signs of a national culture, while the very act of the narrative performance interpellates a growing circle of national subjects. In the production of the nation as narration there is a split between the continuist, accumulative temporality of the pedagogical, and the repetitious, recursive strategy of the performative. It is through this process of splitting that the conceptual ambivalence of modern society becomes the site of writing the nation. (297)

Mientras Monsiváis enuncia el desliz entre la experiencia vivida del marginado y la norma nacional contra la cual se mide llevando a cabo una performance repetida del punto de vista de un nuevo otro en su crónica, no ve la condición igualmente inadecuada de todo mexicano para ejecutar la norma. Su actuación retórica se limita a reposicionar el espacio del marginado, abriéndolo a la participación inclusiva de las masas pero sin resolver la

\footnotetext{
${ }^{28}$ Sánchez-Prado también hace referencia a Bhabha en su lectura de Los rituales del caos: "Monsiváis plantea una nueva idea de nación construida más desde lo performativo que desde lo pedagógico" (22).
} 
condición de todo sujeto de enfrentarse imperfectamente con el ideal de lo que constituye “lo mexicano". Aunque el humor que utiliza se extiende a toda la sociedad-e incluso llega a la autocrítica- el relajo del cual depende la liberación del sujeto está construido sobre bases inestables. Las prácticas del presunto sujeto mexicano del centro nunca se mencionan directamente en Los rituales del caos, pero se presume en todo momento su concordancia con el ideal nacional. Puesto que el fin de la crónica es posibilitar una dimensión nacional de prácticas alternativas que existan en el mismo nivel que las prácticas normativas pero fuera de ellas, Monsiváis describe los rituales caóticos de los márgenes sin explicar por qué estas alternativas periféricas realmente lo son. La diferencia entre la norma nacional y los niveles marginados nunca se explicita, sino que se presume. A lo largo del texto se supone la existencia de un centro, un espacio en el que se manifiesta espectralmente la práctica contra la cual adquieren sentido contestatario la diversión y el relajo del marginado. Esta idea del centro, que el lector imagina como el orden normativo y opuesto a lo caótico marginal, coincide con lo que Bhabha llama lo pedagógico: por el peso acumulado de normas y valores tradicionales “entendidos” sin ser explicitados, el espacio vacío del centro se llena simultáneamente con un ideal de lo que es la nación y con la idea imaginada de lo que debe ser la norma. El espacio de poder sugerido por la presentación de ritos “alternativos" ejecutados por sujetos marginados postula un centro en el que reside ese ideal no articulado, escamoteando de ese modo la diferencia entre la norma ideal y la experiencia concreta del sujeto del llamado “centro".

Esta abstracción del centro como una práctica normativa-ideal hace inalcanzable la libertad del sujeto marginado -o de cualquier sujeto cuyo nacionalismo no coincide con la norma-, pues la resistencia se opone a un referente siempre esquivo e inconfrontable. Cada vez que se presenta una práctica performativa alternativa, el ideal al cual se opone también se transforma, como todo ideal, para mantenerse siempre a una distancia adecuada de lo performativo. Al asignar al relajo, la ironía y el humor un espacio textual liberador, Monsiváis intenta transformar la percepción y la práctica de la vida mexicana de sus lectores; pero el desborde del discurso normativo de sus límites parentéticos y la interpenetración del humor y la seriedad en el texto son síntomas de la condición de mutua dependencia estructural entre centro y periferia que desmiente la naturaleza “divertida” e independiente del nuevo margen como resistencia posible. De igual manera, la invisibilidad del centro/ideal en el texto subraya la persistencia de la ruptura entre lo performativo y lo pedagógico que requiere una suspensión constante de la realización social de la libertad que busca Monsiváis para el sujeto mexicano. ${ }^{29}$

\footnotetext{
${ }^{29}$ Casi una década más tarde, en el mundo pos-11 de septiembre dominado por las influencias estadounidenses en la cultura, política y economía mexicanas, Monsiváis postula una transformación hacia el "posnacionalismo" que reconoce "la idea omnipresente del fracaso de la nación oficial” ("De la sociedad” 43). Aceptando el predominio de un nuevo ideal -la cultura estadounidense-Monsiváis dice: "Si el nacionalismo tradicional es ya irretornable, lo inevitable en México, al margen de los comportamientos de su gobierno, es la defensa esencial de sus intereses nacionales, sin agresiones ni teatralización radical [...] pero sin ceder en lo tocante a la soberanía, que es decisión primera y última sobre lo que ocurre en el espacio nacional” (46). En esta práctica del “posnacionalismo”, se enfatiza de nuevo la diferencia entre la nación del Estado y la de las masas, aunque frente al ideal de la globalización, incluso la norma oficial mexicana se convierte en una práctica insuficiente que tiene que ser defendida.
} 
En el capítulo final del libro Monsiváis arguye que la situación de México -un país con una enorme población caracterizada por diferencias sociales, económicas, culturales y religiosas que dificultan la noción de una nación unívoca- ha llegado a tornar en presente el futuro apocalíptico normalmente aplazado por las profecías. ${ }^{30}$ En la última "Parábola de las postrimerías”, el narrador sueña con un anciano que le dice: "La esencia de los vaticinios es la consolación por el fraude: el envío de los problemas del momento a la tierra sin fondo del tiempo distante. Observa sin aspavientos el futuro: es tu presente sin las intermediaciones del autoengaño” (249). Monsiváis sugiere que el colapso de la estructura temporal que vuelve presente el futuro profetizado rompería la cadena de aplazamientos y cerraría la brecha entre el ideal -en este caso nihilista pero de todos modos inalcanzable y diferido- y la realidad presente. Pero la coincidencia imaginada de futuro y presente, de lo pedagógico y lo performativo, del centro y el margen, del texto y el lector de las que depende el autor para construir un modelo de liberación que podría activar un cambio en el lector y, por extensión, en la sociedad mexicana, sólo ocurre bajo el signo del apocalipsis, mientras que en su texto se difumina constantemente bajo la presión de un ideal esquivo, abstracto y aplazado.

Quizás sea cierta la afirmación con que Monsiváis termina Los rituales del caos: "La pesadilla más atroz es la que nos excluye definitivamente” (250). ${ }^{31}$ En el retrato de la sociedad que crea el autor, la situación del sujeto mexicano no es ni de exclusión ni de inclusión definitivas, sino la de una representación y de una participación perennemente parciales y pospuestas.

\section{BibLIOGRAFÍA}

Althusser, Louis. "Ideology and Ideological State Apparatuses (Notes towards an Investigation)”. Lenin and Philosophy and Other Essays. Ben Brewster, ed. London: NLB, 1971.

Austin, J.L. How to Do Things with Words. Cambridge: Harvard University Press, 1962. Barradas, Efraín. "Cursi, choteo, guachafita: propuesta para una historia del humor caribeño”. Casa de las Américas 230 (2003): 101-07.

Barthes, Roland. “The World of Wrestling”. Mythologies. Annette Lavers, trad. New York: Hill and Wang, 1972.

Bartra, Roger. La jaula de la melancolía: identidad y metamorfosis del mexicano. México: Grijalbo, 1987.

Benjamin, Walter. The Arcades Project. Howard Eiland y Kevin McLaughlin, trads. Cambridge: Belknap, 1999.

Bhabha, Homi K. "DissemiNation: Time, Narrative, and the Margins of the Modern Nation”. Nation and Narration. New York: Routledge, 1990. 291-322.

\footnotetext{
${ }^{30}$ Margo Glantz identifica el tema del apocalipsis en Los rituales del caos, confirmando nuestra sospecha al proponer que "El caos como en todas las cosmogonías primitivas es en realidad un comienzo, el origen, el origen de un mundo nuevo [...] por eso vivir o caer en el caos es el signo anunciador de un nuevo advenimiento" (sin paginación).

${ }^{31}$ Juan Villoro interpreta esta pesadilla de la exclusión como la ansiedad del cronista de no formar parte del contexto socio-histórico sobre el cual escribe (29).
} 
Castañón, Adolfo. “Un hombre llamado ciudad”. Vuelta 163 (1990): 19-22.

Corona, Ignacio y Beth E. Jörgensen, eds. Contemporary Mexican Chronicle: Theoretical Perspectives on the Liminal Genre. Albany: State University of New York Press, 2002.

"At the Intersection: Chronicle and Ethnography". Contemporary Mexican Chronicle: Theoretical Perspectives on the Liminal Genre. Ignacio Corona y Beth E. Jörgensen, eds. Albany: State University of New York Press, 2002. 123-55.

Corral, Wilfrido. "Culto, popular y masivo según Monsiváis”. Revista de Literatura Mexicana Contemporánea 6/13 (2000): 38-41.

Cossío, María Eugenia. “El diálogo sin fin de Monsiváis”. Hispanic Journal 5/2 (1984): 137-43.

Cotter, Joseph. Troubled Harvest: Agronomy and Revolution in Mexico, 1880-2002. Westport: Praeger, 2003.

Díaz Barriga, Miguel. “The Culture of Poverty as Relajo”. Aztlán 22/2 (1997): 43-65.

Egan, Linda. Carlos Monsiváis: Culture and Chronicle in Contemporary Mexico. Tucson: University of Arizona Press, 2001.

“Neoliberalismo y desaliento en Aires de familia de Carlos Monsiváis”. Revista de Crítica Literaria Latinoamericana 56 (2002): 219-35.

"Play on Words: Chronicling the Essay". Contemporary Mexican Chronicle: Theoretical Perspectives on the Liminal Genre. Ignacio Corona y Beth E. Jörgensen, eds. Albany: State University of New York Press, 2002. 95-122.

Escalante, Evodio. Las metáforas de la crítica. México: Joaquín Mortiz, 1998.

Faber, Sebastiaan. "La metonimia en una crónica de Carlos Monsiváis. Hacia un periodismo democrático”. Literatura Mexicana 10/1-2 (1999): 249-280.

Flores Galindo, Alberto. La ciudad sumergida: aristocracia y plebe en Lima, 1760-1830. Lima: Horizonte, 1991.

Gelpí, Juan. "Walking in the Modern City: Subjectivity and Cultural Contact in the Urban Crónicas of Salvador Novo and Carlos Monsiváis”. Contemporary Mexican Chronicle: Theoretical Perspectives on the Liminal Genre. Ignacio Corona y Beth E. Jörgensen, eds. Albany: State University of New York Press, 2002. 201-20.

Glantz, Margo. “Carlos Monsiváis”. Ciberletras 6. Enero 2002. 13 de enero de 2005 <http://www.lehman.cuny.edu/ciberletras/>.

Kraniauskas, John. "Critical Closeness: The Chronicle-Essays of Carlos Monsiváis”. Mexican Postcards. London: Verso, 1997. ix-xxii.

Kuhlmann, Ursula. “La crónica contemporánea en México: apuntes para su análisis como praxis social”. Revista de Crítica Literaria Latinoamericana 30 (1989): 199-208.

Levi, Heather. "Masked Media: The Adventures of Lucha Libre on the Small Screen”. Fragments of a Golden Age: The Politics of Culture in Mexico Since 1940. Gilbert M. Joseph, Anne Rubenstein, and Eric Zolov, eds. Durham: Duke University Press, 2001. 330-72.

Long, Mary K. "Writing the City: The Chronicles of Salvador Novo". Contemporary Mexican Chronicle: Theoretical Perspectives on the Liminal Genre. Ignacio Corona y Beth E. Jörgensen, eds. Albany: State University of New York Press, 2002. 181200. 
Mañach, Jorge. Indagación del choteo. Rosario Rexach, ed. Miami: Universal, 1991.

Miller, Erica L. “De choteos y choteadores en Indagación del choteo, de Jorge Mañach”. Revista Canadiense de Estudios Hispánicos 28/2 (2004): 377-89.

Monsiváis, Carlos. Salvador Novo: Lo marginal en el centro. $2^{\text {a }}$ edición. México: Era, 2004.

Aires de familia: cultura y sociedad en la América Latina. Barcelona: Anagrama, 2000.

Mexican Postcards. John Kraniauskas, ed. y trad. London: Verso, 1997.

Los rituales del caos. México: Era, 1995.

Entrada libre: crónicas de la sociedad que se organiza. México: Era, 1987.

Escenas de pudor y liviandad. México: Grijalbo, 1981.

Días de guardar [1970]. México: Era, 1971.

“De la sociedad tradicional a la sociedad postradicional”. Imaginarios de nación: pensar en medio de la tormenta. Jesús Martín-Barbero, ed. Bogotá: Ministerio de Cultura, 2001.

Mudrovcic, María Eugenia. “Carlos Monsiváis, un intelectual post-68”. Tradición y actualidad de la literatura iberoamericana. Pamela Bacarisse, ed. Vol. 1. Pittsburgh: IILI, 1994. 295-302.

"Cultura nacionalista vs. cultura nacional: Carlos Monsiváis ante la sociedad de masas”. Hispamérica 79 (1998): 29-40.

Muñoz, Boris y Silvia Spitta, eds. Más allá de la ciudad letrada: crónicas y espacios urbanos. Pittsburgh: IILI, 2003.

Paz, Octavio. El laberinto de la soledad [1950] Enrico Mario Santí, ed. Madrid: Cátedra, 1997.

Pons, María Cristina. “Monsi-caos: la política, la poética o la caótica de las crónicas de Carlos Monsiváis”. Revista de Crítica Literaria Latinoamericana 51 (2000): 12539.

Portilla, Jorge. Fenomenología del relajo y otros ensayos [1966]. México: CREA, 1984.

Rama, Ángel. La ciudad letrada. Hanover: Ediciones del Norte, 1984.

Ramos, Samuel. "El perfil del hombre y la cultura en México” [1934]. Obras completas. Vol. 1. México: U Nacional Autónoma de México, 1975. 89-182.

Sánchez-Prado, Ignacio. “De ironía, desubicación, cultura popular y sentimiento nacional: Carlos Monsiváis en el cambio de siglo”. Revista de Literatura Mexicana Contemporánea 20 (2003): 15-23.

Seaver, Paul W., ed. Essays on Luso-Hispanic Humor. Lewiston: The Edwin Mellen Press, 2004.

Stabb, Martin. The Dissenting Voice: The New Essay of Spanish America, 1960-1985. Austin: University of Texas Press, 1994.

In Quest of Identity: Patterns in the Spanish American Essay of Ideas, 1890-1960. Chapel Hill: University of North Carolina Press, 1967.

Vaughan, Mary Kay. Cultural Politics in Revolution: Teachers, Peasants, and Schools in Mexico, 1930-1940. Tucson: University of Arizona Press, 1997.

Villoro, Juan. “La cultura de masas imita a su profeta”. Ínsula 618-19 (1998): 27-29. 